\title{
Directional Coupler Frekuensi Radio Menggunakan Dua Jalur Asimetris Mikrostrip untuk Sistem Radar $X$-band
}

\author{
Radio Frequency Directional Coupler Using Asymmetric \\ Double Microstrip Transmission Lines \\ for X-band Radar Systems
}

Sri Hardiati* dan Hana Arisesa

Pusat Penelitian Elektronika dan Telekomunikasi, Lembaga Ilmu Pengetahuan Indonesia Komp LIPI Gd 20, Jl Sangkuriang 21/54D, Bandung 40135, Indonesia

\begin{abstract}
Abstrak
Directional coupler frekuensi radio (RF) menggunakan dua jalur mikrostrip asimetris dibahas dan dirancang dengan struktur planar pada substrat duroid 5880. Directional coupler yang diusulkan terdiri dari dua jalur mikrostrip dengan jarak yang relatif dekat. Oleh karena itu, sinyal RF dapat ditransfer dari satu jalur mikrostrip ke jalur mikrostrip lain. Directional coupler telah dianalisis untuk frekuensi yang beroperasi pada daerah $X$-band dengan menggunakan perangkat lunak Advance Design Systems (ADS) dan berhasil dipabrikasi menggunakan proses pabrikasi standar. Dalam pengukuran divais ini, diperoleh koefisien coupling sekitar $20 \mathrm{~dB}$ untuk frekuensi operasional 9,2 sampai 9,9 GHz. Hasil pengukuran mempunyai suatu kesepakatan dengan hasil perhitungan. Berdasarkan hal tersebut, maka directional coupler dapat digunakan untuk sistem radar X-band.
\end{abstract}

Kata kunci: directional coupler, mikrostrip, radar FMCW, X-band.

\section{Abstract}

An radio frequency $(R F)$ directional coupler using asymmetric double microstrip line discussed and designed with a planar structure on 5880 Duroid substrate. The proposed directional coupler consists of two microstrip line with relatively close distance. Therefore, a RF signal can be transferred from one microstrip to other microstrip. The directional coupler was analyzed for X-band operational frequency using Advance Design Systems (ADS) software and successfully fabricated using standard fabrication processes. In device measurement, about 20dB coupling coefficient was obtained for 9.2 to $9.9 \mathrm{GHz}$ operational frequency. The measurement results have good agreements with the calculation results. Based on that, the directional coupler can be used for X-band radar systems.

Keywords: directional coupler, microstrip, FMCW radar, X-band

\section{Pendahuluan}

Directional coupler frekuensi radio yang dikenal dengan RF (Radio Frequency) merupakan komponen pasif yang mempunyai fungsi untuk mendistribusikan sinyal RF pada suatu saluran menjadi dua bagian yang terpisah dan mempunyai kemampuan untuk mengarahkan sinyal dan menggabungkan sinyal.

Directional coupler pada sistem radar FMCW (frequency modulated continues wave) ini mempunyai fungsi untuk menggabungkan bagian tertentu dari daya yang berjalan dalam saluran transmisi melalui suatu port penyalur (through) dan mengambil sebagian sinyal melalui port kopel (couple) untuk proses sinyal IF (intermediate frequency), di mana daya tersebut diperlukan pada sistem radar FMCW. Desain sistem Radar beroperasi dalam band frekuensi yang terbatas pada suatu level daya yang optimum. Pengoperasian radar pada frekuensi atau level power di luar band yang

* Corresponding Author.

Email: ash_egt@yahoo.com

Received: October 14, 2014; Revised: October 31, 2014

Accepted: November 12, 2014

Published: December 30, 2014

(C) 2014 PPET - LIPI

doi : $10.14203 /$ jet.v14.45-50 ditentukan sangat menurunkan efisiensi dari transmitter dan dapat menyebabkan interferensi dengan radar lain.

Sistem radar FMCW tidak memerlukan daya yang besar [1], oleh karena itu pada penelitian ini, arsitektur directional coupler dibentuk dari mikrostrip dengan menggunakan teknik couple line yang bekerja dalam frekuensi $X$-band sesuai dengasn keperluan dalam sistem radar FMCW tersebut. Directional coupler mikrostrip dengan teknik coupled-line secara luas digunakan dalam sistem RF, di mana beberapa metode dan konfigurasi telah dilakukan percobaan untuk memperbaiki nilai coupling.

Dalam paper ini prosedur alternatif untuk meningkatkan nilai coupling dari directional coupler mikrostrip yaitu dengan menerapkan teknik parallel couple line dengan model dua jalur transmisi mikrostrip asimetris. Desain ini memiliki bentuk sederhana karena hanya terdiri dua jalur. Jalur pertama berbentuk lurus dan jalur kedua berbentuk menyerupai bentuk $U$, di mana kedua jalur dipisahkan dengan suatu jarak yang relatif cukup dekat dan kedua jalur tersebut terletak pada satu bidang planar tanpa memerlukan ada penambahan komponen lain. Selain itu, pabrikasi directional coupler hanya memerlukan proses yang sederhana. 
Dari hasil penelitian, directional coupler mikrostrip ini memperoleh hasil coupling sebesar $20 \mathrm{~dB}$, pada frekuensi $\mathrm{f}=9860 \mathrm{MHz}$, hal tersebut sesuai dengan keperluan sistem radar $X$-band dengan daya rendah.

\section{PRINSIP KeRJA DIRECTIONAL COUPLER}

Apabila dua saluran transmisi berdekatan, maka akan menyebabkan interaksi medan elektromagnetik satu dengan yang lain, daya dapat dikopel antara saluran tersebut. Saluran yang terkopel tersebut digunakan untuk konstruksi directional coupler.

Directional coupler merupakan komponen pasif yang digunakan untuk mendistribusikan sinyal RF pada suatu saluran menjadi dua bagian yang terpisah dan mempunyai kemampuan untuk mengarahkan sinyal dan mengkopel (coupled) sinyal. Mekanisme sistem kopel suatu daya yang ditransmisikan dengan suatu jumlah daya yang telah diketahui yaitu dengan cara menempatkan posisi saluran yang cukup berdekatan, sehingga energi yang melalui suatu port penyalur (through) akan dipisahkan ke port yang lain.

Ada beberapa jenis directional coupler dalam bentuk yang berbeda. $R F$ directional coupler dapat dibuat dengan beberapa teknik konstruksi antara lain berupa mikrostrip, koaksial, elemen lumped, waveguide, yang secara umum divais ini dirancang dan dikemas sekecil mungkin.

Konfigurasi dasar dari directional coupler tunggal pada umumnya menggunakan 4 port [2] mengilustrasikan 2 saluran transmisi paralel. Directional coupler dapat dijelaskan dengan bantuan dari Gambar 1 yang menunjukkan simbol directional coupler dan definisi dari port.

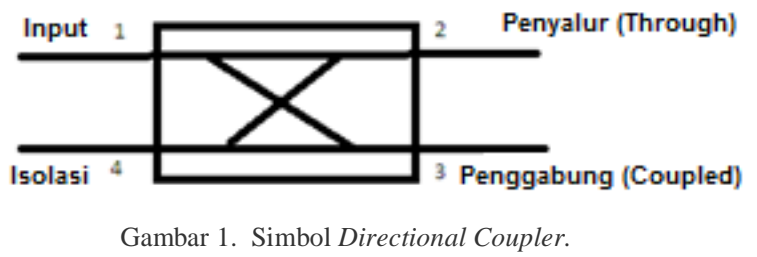

Keterangan:

- Port 1: port insiden.

- Port 2: port penyalur (through).

- Port 3: port yang dikopel (couple port).

- Port 4: port yang diisolasi (isolated port)

Adapun pengoperasian dasar directional coupler di atas menurut [3] dapat diuraikan sebagai berikut:

- Daya dari port 1 dikopel ke port 3 yang dinamakan coupled port.

- Daya input dikirim ke port 2 dinamakan port penyalur (through port).

- Directional coupler ideal, tidak ada daya yang dikirim ke port4 yang disebut port isolasi.

Secara ideal daya ke dalam port 1 hanya muncul pada port 2 dan 3 dan tidak ada daya pada port 4, tetapi dalam realisasinya masih ada beberapa kebocoran daya pada port.

Faktor penting yang menjadi ciri dari directional coupler adalah sebagai berikut:

Pada port 1 dari sinyal P1 dan daya output P2, P3 dan $\mathrm{P} 4$, maka insertion loss (IL) dapat dinyatakan dengan Persamaan 1 [3], [4]:

$$
I L=10 \log \frac{\mathrm{P}_{1}}{\mathrm{P}_{2}}=-10 \log \mathrm{S}_{21}
$$

Kinerja directional coupler dapat dievaluasi dengan mencakup coupling, directivity, reflection loss dan kesepadanan impedansi (impedance matching) pada semua port, apabila port lain diterminasikan pada beban yang sepadan (match). Secara umum directional coupler didesain untuk menunjukkan faktor coupling yang diinginkan [2] dan merupakan nilai yang menunjukkan bagian daya keseluruhan yang ditransfer dari saluran penyalur ke coupler. Oleh karena itu directional coupler memerlukan coupling yang kuat untuk mengurangi efek pada daya yang ditransmisikan dan directvity yang tinggi untuk menekan interferensi dari sinyal yang dipantulkan.

Teori desain coupler untuk saluran TEM (transverse electric magnetic) seperti couple line directional coupler berdasarkan asumsi dari kecepatan fase (phase velocity) dari mode propagasi genap (even) dan ganjil (odd) [4] dibentuk dengan menggunakan 2 saluran transmisi dengan jarak yang cukup berdekatan. Saluran utama dan saluran kedua dipisahkan dengan jarak fisik yang diperhitungkan, hal ini menentukan faktor coupling dari divais tersebut. Oleh karena saluran mikrostrip yang terkopel mempunyai kecepatan fasa untuk mode even dan odd tidak sama, maka desain directional coupler dimodifikasi dengan struktur parallel couple-line sedemikian sehingga kecepatan fasa ke dua mode tersebut disamakan [5].

\section{MIKROSTRIP DIRECTIONAL COUPLER}

Mikrostrip adalah jenis saluran transmisi elektrik untuk membawa gelombang elektromagnetik. Saluran mikrostrip terdiri dari 3 lapisan yaitu jalur konduktor (conducting strip), dielektrik and bidang ground dan dibuat menggunakan substrat dielektrik dengan teknologi printed circuit board (PCB) berdasarkan etching.

Pada saluran mikrostrip, medan elektromagnetik (EM) ada sebagian pada udara yang berada sekitar bahan dielektrik dan sebagian di antara bahan dielektrik itu sendiri [6]. Ada 3 jenis loss pada saluran transmisi mikrostrip yaitu: Loss konduktor, Loss Radiasi, Loss dielektrik [6], [7].

Tipe perambatan pada saluran transmisi yaitu TEM, TE (tranverse electric), dan TM (transverse magnetic). Pada TEM, medan magnet $(\mathrm{H})$ dan medan listrik $(\mathrm{E})$, gelombang saling tegak lurus dan melintang terhadap sumbu perambatannya, sedangkan tipe TE dan TM salah satu komponen medannya searah dengan sumbu perambatannya [8], [9]. Saluran transmisi mikrostrip mempunyai karakteristik sendiri yang berpengaruh, antara lain terhadap impedansi karakteristik, loss saluran transmisi tersebut, dan kecepatan propagasi. Pada saluran transmisi mikrostrip, impedansi karakteristiknya dapat dihitung dengan menganggap gelombang elektromagnetik pada saluran merupakan quasi transverse (TEM) [10], karena bahan dielektrik tipis dan jarak pemisah antara saluran transmisi yang tidak homogen relatif kecil terhadap panjang gelombang, maka mode propagasi dapat dianggap dekat dengan TEM. Waktu propagasi TEM dalam saluran mikrostrip mempunyai hubungan yang erat dengan 
variable-variabel lain seperti lebar strip konduktor, tinggi bahan dielektrik, dan $\varepsilon_{\mathrm{r}}$. Impedansi karakteristik dari microstrip line dapat dihitung menggunakan persamaan Wheeler [6].

Dalam saluran mikrostrip, panjang gelombang saluran transmisi $\lambda$ menurut [6] diberikan dengan Persamaan 2.

$$
\lambda=\lambda_{0} /\left(\varepsilon_{e f f}\right)^{0,5}
$$

$\varepsilon_{\text {eff }}$ adalah konstanta dielektrik yang efektif tergantung pada konstanta dielektrik dari bahan substrat dan dimensi fisik saluran mikrostrip. $\lambda_{0}$ adalah panjang gelombang di ruang bebas.

Couple lines digunakan dalam directional coupler, di mana saluran kopel terjadi apabila dua saluran transmisi tanpa pelindung dan berdekatan jaraknya, sehingga energi dari salah satu saluran mengalir ke yang lain. Energi tersebut akan terkopel antara saluran, hal tersebut disebabkan adanya interaksi medan elektromagnetik satu sama lain. Bila saluran mikrostrip dalam satu bidang dan paralel satu sama lain dinamakan parallel couple line yang disebut juga struktur edgecouple [10], mempunyai mode even dan odd dan menghasilkan impedansi mode even $\left(\mathrm{Z}_{0 \mathrm{e}}\right)$ dan impedansi mode odd $\left(\mathrm{Z}_{0 \mathrm{o}}\right)$. Coupling antara saluran simetris dapat ditentukan dengan bentuk kecepatan fasa dan impedansi karakteristik dari couple line dari mode even dan mode odd [10].

Dalam desain coupler, koefisien coupling (k) dan impedansi karakteristik $\mathrm{Z}_{0}$ menentukan impedansi mode even dan mode odd. Dimensi coupler dapat dihitung [10] untuk panjang fisik $l$ dari coupler diberikan dengan Persamaan 3.

$$
l=\lambda_{g} / 4
$$

$\lambda_{\mathrm{g}}$ merupakan panjang gelombang pemandu TEM dalam medium saluran transmisi pada frekuensi yang diinginkan. Jika Coupling ditentukan $C \mathrm{~dB}$, maka koefisien coupling menurut [10] ditentukan dengan Perasamaan 4.

$$
k=10^{-C / 2}
$$

\section{IV.}

\section{Perancangan}

Untuk menentukan kinerja directional coupler, spesifikasi penting yang perlu diperhatikan yaitu insertion loss saluran utama, di mana hasil insertion loss minimum secara teori tergantung pada tingkat coupling antara saluran utama dan port kopel.

Metode desain directional coupler memerlukan informasi dari impedansi port, coupling, dan frekuensi operasional. Secara umum directional coupler didesain untuk memperoleh coupling 20-40 dB [8]. Pada penelitian ini directional coupler didesain untuk diterapkan dalam sistem radar FMCW yang memerlukan coupling sebesar $20 \mathrm{~dB}$ pada frekuensi $X$ band dengan frekuensi tengah $9,86 \mathrm{GHz}$ dan impedansi port diambil $50 \Omega$. Directional coupler menggunakan saluran transmisi yang disebut dengan mikrostrip yaitu terdiri dari dua saluran transmisi yang diimplementasikan sebagai jalur PCB, di mana masingmasing dibentuk berupa jalur dielektrik antara permukaan plat konduktif yang ditempatkan secara substansial satu sama lain dengan jarak satu sama lain berdekatan.

Ilustrasi dari desain directional coupler dengan teknik parallel couple line seperti ditunjukkan pada Gambar 2, merupakan sistem kopel jenis uniform dan asimetris. Dari gambar tersebut dapat dilihat bentuk saluran, yang pertama berbentuk lurus dan saluran dielektrik ke dua berbentuk menyerupai huruf U. Pada saluran utama ujung-ujung dari saluran tersebut dinamakan port 1 dan port 2 dan pada ujung saluran sekunder dinamakan port 3 dan port 4 .

Desain directional coupler mikrostrip dengan teknik parallel couple line ini mempunyai 2 analisis pendekatan, yaitu mode odd dan mode even [3], [9], dan dibuat dengan parameter-parameter yang penting di dalam melakukan perancangan coupler yakni lebar patch (W), gap atau jarak antara kedua patch (S), panjang patch (L), yang identik seperti terlihat pada Gambar 2. Adapun parameter lainnya yang berpengaruh yaitu $\mathrm{h}$ yang merupakan tinggi substrat dan $\mathrm{t}$ adalah tebal patch substrat yang digunakan.

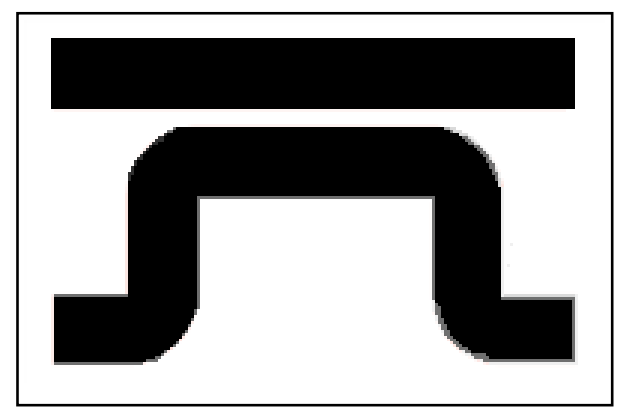

Gambar 2. Ilustrasi Directional Coupler Dengan Teknik Parallel Couple Line.

Dalam penelitian directional coupler ini simulasi maupun pabrikasi menggunakan bahan substrat duroid 5880 yang mempunyai konstanta dielektrik 2,2 dan mempunyai tebal $1,5 \mathrm{~mm}$.

Dengan bantuan software Advance Design System $(A D S)$, maka desain directional coupler dengan teknik parallel couple line dan dengan struktur dua jalur elektris yang tidak simetris diperoleh dimensi seperti ditunjukkan pada Gambar 3.

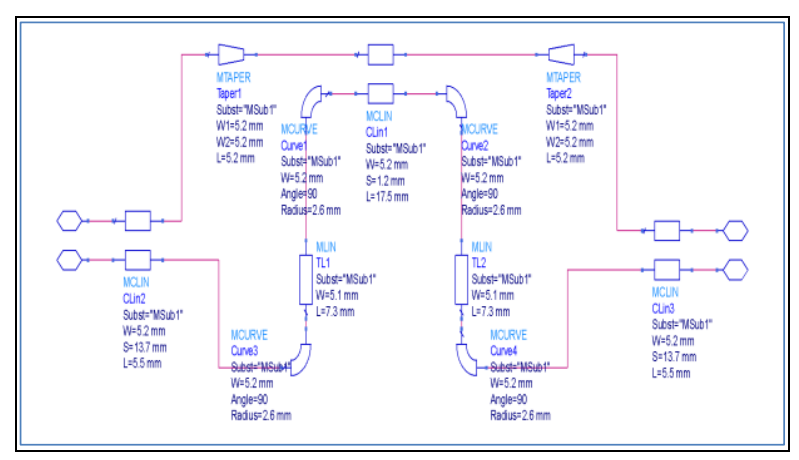

Gambar 3. Diagram Skematik Dimensi dari Jalur Dielektrik Desain Directional Coupler.

\section{Hasil Dan Pembahasan}

Hasil secara simulasi dan pengukuran dari desain directional coupler tersebut diuraikan dalam bagian ini. 


\section{A. Hasil Simulasi}

Dari hasil simulasi yang ditunjukkan pada Gambar 4, diperoleh hasil seperti dalam Tabel 1.

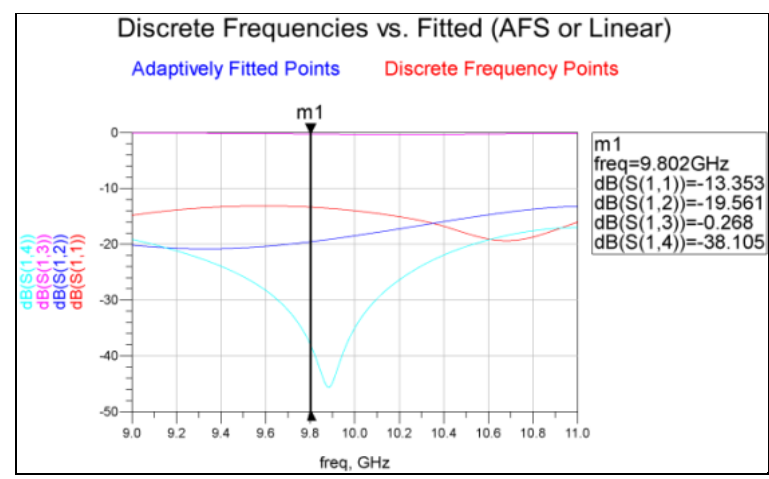

Gambar 4. Hasil Simulasi Directional Coupler.

TABEL 1

HASIL SiMUlasi DiRECTIONAL COUPLER PADA FREKUENSI 9,802 GHz

\begin{tabular}{|l|l|c|}
\hline No. & Parameter & $\begin{array}{c}\text { Hasil simulasi pada Fekuensi } \\
\mathbf{9 , 8 0 2} \mathbf{~ G H z}\end{array}$ \\
\hline 1 & $\mathrm{~S}_{11}$ & $-13,353 \mathrm{~dB}$ \\
\hline 2 & $\mathrm{~S}_{12 \text { (trough) }}$ & $-0,268 \mathrm{~dB}$ \\
\hline 3 & $\mathrm{~S}_{13 \text { (coupling) }}$ & $-19,561$ \\
\hline 4 & $\mathrm{~S}_{14 \text { (Isolasi) }}$ & $-38,105$ \\
\hline
\end{tabular}

Hasil simulasi directional coupler dengan arsitektur parallel couple line dijelaskan dan ditunjukkan dalam Gambar 4, di mana dapat terlihat bahwa insertion loss $\left(\mathrm{S}_{21}\right)$ berpengaruh pada port isolasi yang akan mengurangi level noise. Dari gambar tersebut didapat hasil coupling 19,561 dB dan isolasi 38,105 dB.

Directivity $(D)$ dari directional coupler dengan arsitektur berbentuk $\mathrm{U}$ dapat dihitung dengan menggunakan Persamaan 5 berikut ini.

$$
D=I-C
$$

di mana $I$ adalah isolasi dan $C$ adalah coupling. Jika nilai isolasi dan coupling masing-masing adalah 38,105 $\mathrm{dB}$ dan 19,561 dB, maka secara simulasi memperoleh directivity sekitar 18,544 dB. Dari Gambar 4 juga diperoleh insertion loss dan reflection loss pada port penyalur dari directional coupler yang masing-masing adalah $-0,268 \mathrm{~dB}$ dan $-13,353 \mathrm{~dB}$.

Secara simulasi hasil menunjukkan bahwa directional coupler yang diusulkan dengan teknik parallel couple line mempunyai efek isolasi yang unggul dan directivity cukup bagus.

\section{B. Fabrikasi dan Pengukuran}

\section{1) Hasil Realisasi Directional Coupler.}

Desain directional coupler dengan arsitektur 4 port, terdiri dari 2 saluran dieklektrik. Saluran dialektrik yang pertama berbentuk jalur lurus dan yang ke dua menyerupai bentuk U. Realisasi desain tersebut ditunjukkan pada Gambar 5.

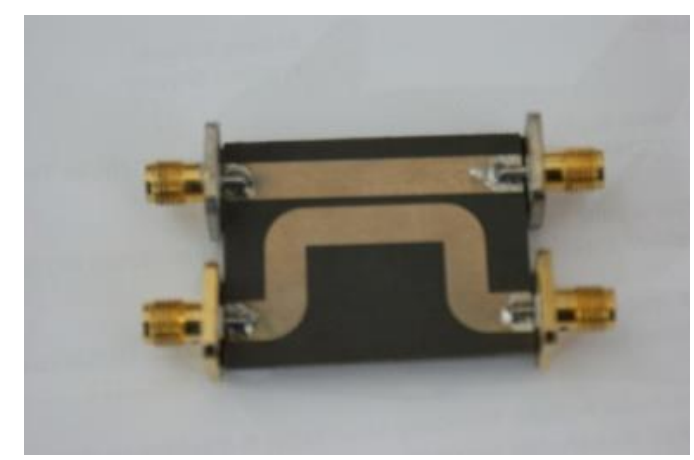

Gambar 5. Prototipe Directional Coupler Parallel Couple Line.

\section{2) Hasil Pengukuran}

Hasil pengukuran directional coupler pada frekuensi 9,863750 GHz ditunjukkan pada Tabel 2 serta Gambar 6, Gambar 7, Gambar 8, dan Gambar 9.

TABEL 2

Hasil PengukuRAn DiRECTIONAL COUPLER

\begin{tabular}{|l|l|c|}
\hline No. & \multicolumn{1}{|c|}{ Jenis Pengukuran } & $\begin{array}{c}\text { Frekuensi: } \\
\mathbf{9 , 8 6 3 7 5 0} \mathbf{~ G H z}\end{array}$ \\
\hline 1 & $\mathrm{~S}_{11 \text { (koefisien refleksi } \text { forward) }}$ & 1,635 \\
\hline 2 & $\mathrm{~S}_{22 \text { (Koefisien refleksi reverse) }}$ & 1,569 \\
\hline 3 & Coupling & $-20,531 \mathrm{~dB}$ \\
\hline 4 & Through & $-0,710 \mathrm{~dB}$ \\
\hline
\end{tabular}

a) Hasil Pengukuran $S_{11}$

Hasil pengukuran $S_{11}$ directional coupler disajikan pada Gambar 6.

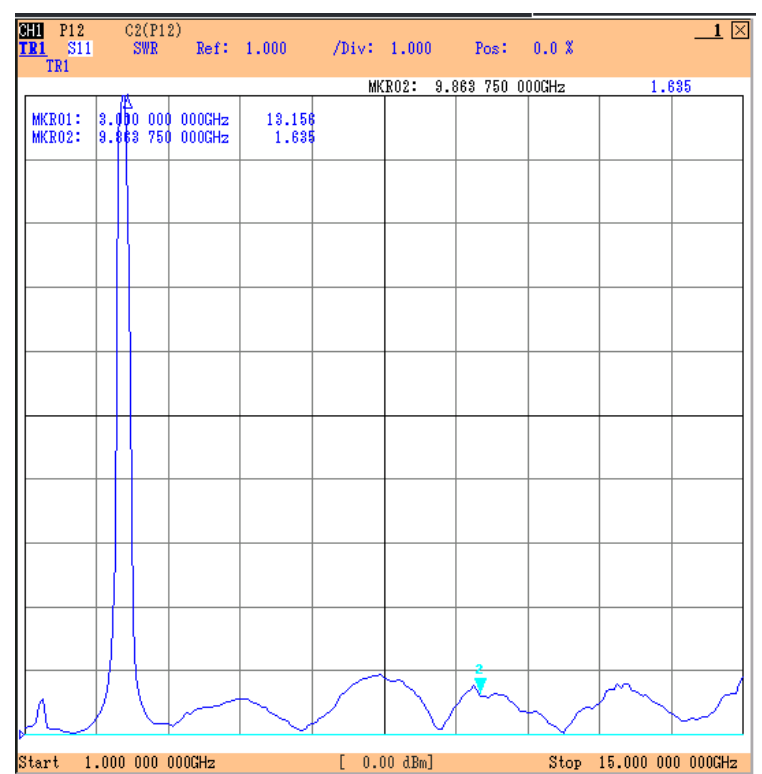

Gambar 6. Hasil Pengukuran $\mathrm{S}_{11}$ Directional Coupler

b) Hasil Pengukuran $S_{22}$

Hasil pengukuran $\mathrm{S}_{22}$ directional coupler disajikan pada Gambar 7. 


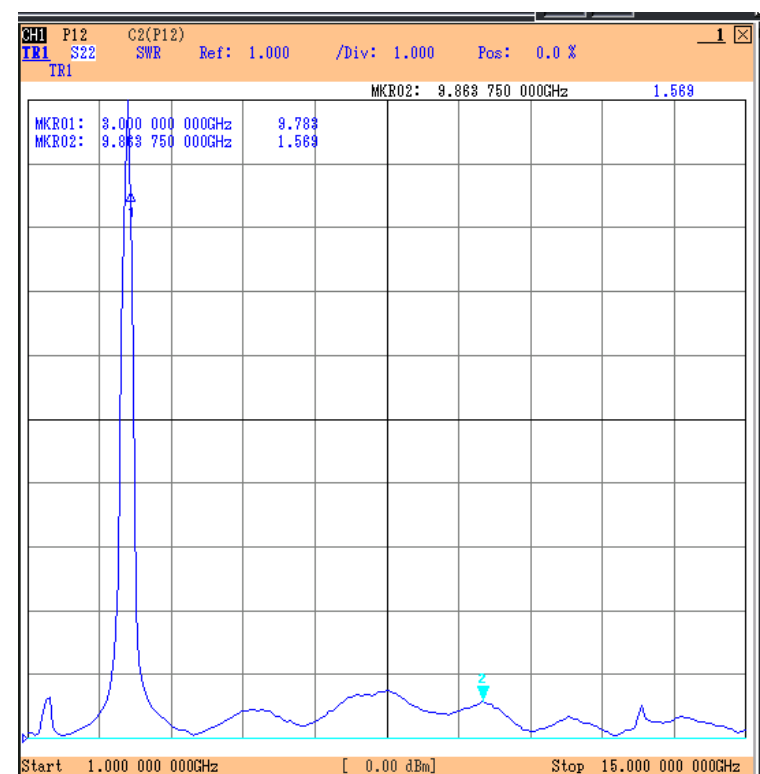

Gambar 7. Hasil pengukuran $\mathrm{S}_{22}$ Directional Coupler.

c) Hasil Pengukuran Coupling

Hasil pengukuran port coupling dari directional coupler disajikan pada Gambar 8.

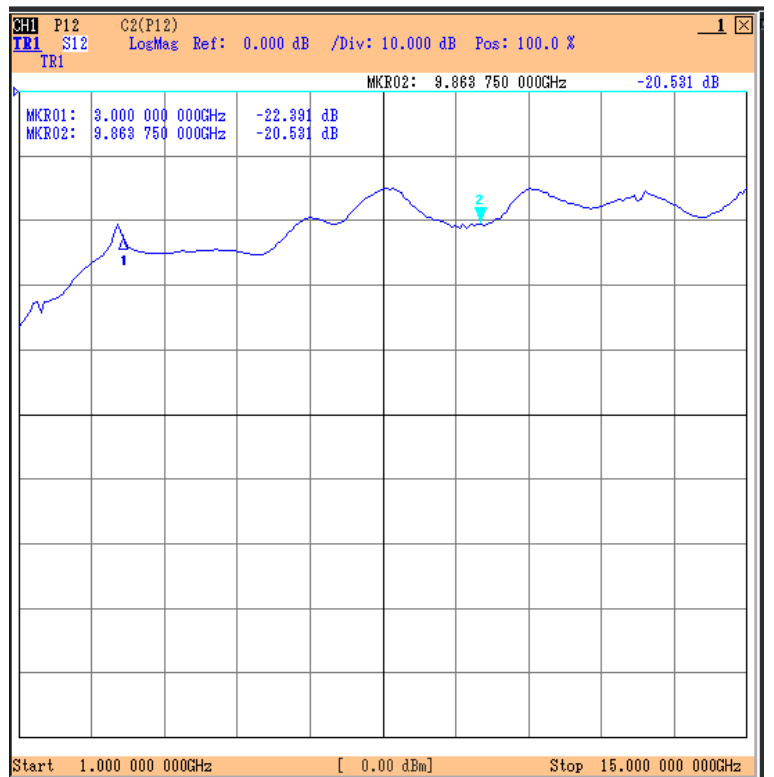

Gambar 8. Hasil Pengukuran pada Port Coupling dari Directional Coupler.

Hasil pengukuran dari realisasi desain directional coupler pada frekuensi $9,863 \mathrm{GHz}$ memperoleh coupling sebesar $-20,531 \mathrm{~dB}$. Bila dilihat pada Gambar 8 , Hasil coupling $\approx 20 \mathrm{~dB}$ didapatkan pada rentang frekuensi 9,2-9,9 GHz. Faktor coupling tinggi akan menyebabkan insertion loss kecil dalam saluran utama. Losses biasanya meningkat disebabkan oleh material yang mempunyai konstanta dielectrik tinggi, mempunyai loss tangents (tan $\delta$ ) tinggi, dan juga oleh impedansi karakteristik yang tidak sama.

Koefisien refleksi arah maju (forward) $\mathrm{S}_{11}$ adalah 1,635 dan koefisien refleksi arah balik (backward) $\mathrm{S}_{22}$ adalah 1,569, hal ini menunjukkan bahwa daya directional coupler yang direfleksikan tidak terlalu besar, sehingga akan meminimalkan gangguan untuk saluran transmisi.

\section{d) Hasil Pengukuran Through}

Hasil pengukuran through dari directional coupler disajikan pada Gambar 8.

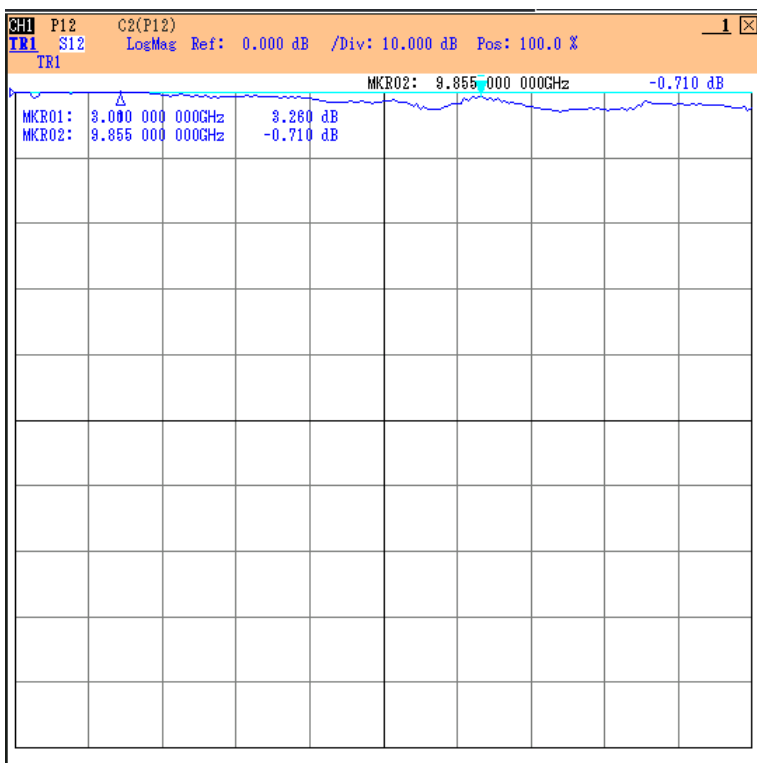

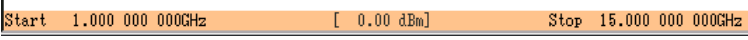

Gambar 9. Hasil Pengukuran Port Penyalur (Through) Directional Coupler.

Berdasarkan hasil penelitian faktor yang paling dominan untuk mendapatkan nilai coupler yang bagus kemampuanya adalah dengan mengatur jarak jalur transmisi yang semakin dekat, sehingga seluruh energi elektromagnetik dapat ditransfer secara optimal. Tetapi pengaturan jarak tersebut terbatas karena semakin dekat jarak antara kedua saluran tersebut, akan menghadapi kesulitan dalam pabrikasi directional coupler. Adapun alternatif yang lain untuk mendapatkan coupling yang kuat, struktur directional coupler mikrostrip couple line harus mempunyai phase velocity dari mode propagasi odd dan even yang sama. Untuk keperluan tersebut substrat dielectrik dari struktur directional coupler harus homogen, tetapi pada saluran mikrostrip medan elektromagnetik tidak homogen, karena ada sebagian udara dan sebagian di dalam substratnya sendiri. Agar memperoleh kondisi homogen maka diperlukan struktur geometri yang tertutup. Untuk mengatasi hal tersebut diperlukan desain directional coupler dengan metode stripline dengan tujuan agar phase velocity dari dua mode yaitu mode odd dan even adalah sama, sehingga memperoleh performance yang lebih bagus dan nilai coupling yang lebih kuat.

\section{KESIMPULAN}

Hasil pengukuran dari directional coupler dengan teknologi mikrostrip yang dibentuk dengan dua jalur transmisi mikrostrip asimetris dan terletak pada satu bidang dan sisi bidang yang lain dipergunakan sebagai grounding, di mana bidang satu dengan yang lain dipisahkan oleh suatu substrat dielektrik memperoleh faktor coupling sebesar $\approx 20 \mathrm{~dB}$, koefisien refleksi arah forward 1,635, dan arah backward 1,569. Berdasarkan hasil pengukuran tersebut, directional coupler ini dapat dipergunakan untuk radar $X$-band sistem FMCW, karena sistem radar tersebut tidak memerlukan daya yang besar. Selain itu juga dapat diestimasikan bahwa 
directional coupler yang didesain dapat diterapkan pada sistem komunikasi yang bekerja pada frekuensi 9,2-9,9 $\mathrm{GHz}$.

\section{UCAPAN Terima KaSIH}

Penulis mengucapkan terima kasih sebesarbesarnya kepada PPET-LIPI yang telah memberikan fasilitas dalam melakukan penelitian directional coupler ini.

\section{Daftar Pustaka}

[1] M. I. Skolnik, Introduction to Radar System, 3rd ed., New York, USA: Mc Graw Hill, 2001.

[2] K. Chang, RF and Microwave Wireless Systems, New York, USA: John Wiley \& Sons, 2000.

[3] D. M. Pozar, Microwave Engineering, 2nd ed., New York, USA: John Wiley \& Sons, 2001.
[4] M. L. Edward. (2014). Calibration and measurements of sparameters, in Microwave \& RF circuits: analysis, design, fabrication \& measurement. [Online]. Available : http://www.ebook2.jp/ebookbuilder/ebook/user/smatabi/testbook 20120717/page/lmg/20120717150707.pdf

[5] T. Hu, D. Li, L. Cao, B. Qin, J. Yang, T. Yu, and J. H. Huazhong, "Design and simulation of microstrip directional coupler with tight structure and high directivity", Proceeding of PAC 09, Vancouver, BC, Canada, 2009, pp, 1677-1679.

[6] L. G. Maloratsky, "Revieving the basics of microstrip lines", Microwave \& RF, pp. 79-86, March 2000.

[7] E. H. Fooks and R. A. Zakarevicius, Microwave Engineering Using Microstrip Circuit, New Jersey, USA: Prentise Hall, 1990.

[8] O. P. Gandhi, Microwave Engineering and Application, New York, USA: Pergamon Press, 1981.

[9] R. E. Collin, Foundations of Microwave Engineering, 2nd ed., New York, USA: McGraw-Hill International Edition, 1992.

[10] R. K. Mongia, I. J. Bahl, P. Bhartia, and J. Hong, $R F$ and Microwave Coupled-Line Circuits, 2nd ed., Norwood, USA: Artech House Inc., 2007. 